\title{
Human rights protection on the internet in Russia and abroad
}

\author{
Natalia Kovaleva*1, Svetlana Kulikova $^{2}$, Natalia Zhirnova ${ }^{3}$ and Tatiana Rudchenko ${ }^{4}$ \\ ${ }^{1}$ Saratov State Law Academy, Saratov, Russia, kovaleva.natalia@mail.ru \\ ${ }^{2}$ Saratov Chernyshevsky National Research State University, Saratov, Russia, kulikovasveta@inbox.ru \\ ${ }^{3}$ Saratov State Law Academy, Saratov, Russia, zhirnowanata@yandex.ru \\ ${ }^{4}$ Saratov State Law Academy, Saratov, Russia, rudchenko27@yandex.ru
}

\begin{abstract}
The article focuses on the analysis of legal protection of personal, political, labor, educational and other rights, freedoms and legitimate interests of citizens on the Internet, as there are generally recognized problems related to their violation by individuals or various organizations. The authors analyze how citizens' rights, such as the right of access to the Internet (the right to the internet connection, the right to IT neutrality, the right to availability of internet service, the right to comfortable usage of internet services, the right not to be disconnected) the right to digital identity (the possibility to manage internet data of private persons), the right to anonymity (the possibility of carrying out certain actions under a false name without revealing personal data that would allow the person to be identified), the right to discard unwanted information (to protect oneself against spam), the right to be forgotten, right to safe internet use, both in the technological as well in the contextual meaming, are declared and implemented on the Internet.
\end{abstract}

\section{Introduction}

82 million people - 66 percent of Russia's population use the Internet [1] An essential feature of modern social development is the general digitization of economic, political, communicative and other social relations which are carried out via the Internet. These relations of course require legal regulation that must take into account the specifics of the legal and technological nature of the electronic environment [2].

\section{Problem Statement}

A lot of personal, political, labor, educational and other rights and freedoms are implemented on the Internet which creates problems related to violation of citizens' rights and freedoms by individuals or different types of organizations that may pursue profit-seeking or destructive goals (e.g. spreading extremist ideas or recruiting individuals for terrorist groups) and be under the jurisdiction of various states [3].

The model law "On the Basics of Internet Regulation", which was adopted at the 36th plenary session of the Interparliamentary Assembly of the CIS member states on 16 May 2011 (revised on 25 November 2016) gives the following definition of the Internet: "Internet is a global information and telecommunications network that connects information systems and telecommunications networks from different countries via a global address system based on the use of IP complexes (Internet Protocol) and TCP complexes (Transmission Control Protocol) and enables the use of various forms of communication, including the ones that make information available to an unlimited number of people. "The rights and obligations of companies that are active on the Internet are defined in the Federal Act No. 149-Federal Law from 27 July 2006 "On Information, Information Technologies and Information Protection" (hereinafter: the Information Act). The aforementioned act defines the legal status of such companies as website owners, hosting providers, search engine operators, owners of news aggregators, owners of audiovisual services, etc. However, the status of a user on the Internet is not defined in the Information Act. The entirety of his/her rights and obligations is regulated by a large number of regulations, permissions and prohibitions, which are established to some extent in the legislation and govern relations in the field of information technologies [4].

\section{Research Questions}

The "Guidelines on Human Rights for Internet Users", adopted by the Committee of Ministers of the Council of Europe in 2014 are of certain interest. They attempt to create a set of rights for an ordinary person who uses various internet services and neither has a special legal status nor any legal, cybernetic or IT expertise.

The Guidelines name the following distinctive rights of internet users:

- the right to access the Internet,

- freedom of expression and information,

\footnotetext{
*Corresponding author: kovaleva.natalia@mail.ru
} 
- the right of assembly, association and participation,

- the right to privacy and data protection,

- the right to education and literacy,

- the right to special protection of children and young people when using the Internet,

- the right to effective means of protecting their internet rights.

The analysis of modern Russian and foreign legislation, recommendations of international bodies for the protection of human rights, as well as the scientific positions of Russian and foreign scientists allow the conclusion that two groups of rights of internet users can be distinguished: first, new digital rights, the appearance of which is based on the legal nature the Internet and second, traditional rights, the implementation of which changes significantly with the transition to the electronic environment [5-6].

\section{Purpose of the Study}

The purpose of this study is to determine the informational and legal status of a person as a citizen on the Internet.

\section{Research Methods}

This study is an analysis of the Russian and international laws that regulate the contemporary legal issues arising from the information technologies playing an increasing role in today's world.

During this study the authors have analyzed over 20 sources about the realization of rights and legitimate interests of people on the Internet.

The authors have applied the following scientific methods:

- a formal-legal method for determining the features and analyzing the definition of a person's "right to

access the Internet";

- a comparative method for comparing the laws on the realization of information rights of citizens in Russian

Federation and other countries;

- a structural analysis method for analyzing the features of the term "right to internet access" as a structural

element of a more general term "right to information";

- an informative approach - when analyzing any object, process or phenomenon in nature and human society

the primary object is determining and analyzing its specific information aspects that strongly influence its current state and development.

\section{Findings}

The contemporary understanding of the right to internet access consists of:

- right to the internet connection: all citizens who wish to be connected to the Internet should have this opportunity. This right corresponds to the duty of the state to enable internet connection for all citizens regardless of their place or residence, so internet connection should be possible even in rural areas and remote regions of the country. According to Part 1 of Article 57 of the Federal Law "About Means of Communication" from 7 July 2003 providing access to the Internet is a universal connection service that must be provided by the state for all its citizens;

- right to IT neutrality or right to protection from technological discrimination: every citizen must have the opportunity to use the information technologies that correspond to his goals and interests and have guaranteed access to the information resources they need. Article 3 of the Russian Law about Information prohibits passing any legislation to grant privileges to certain information technologies compared to the others.

The issue of net neutrality has been actively discussed lately. Internet providers have the opportunity to enable faster connection for certain resources while slowing it down for others for different groups of consumers. Such actions are viewed by some experts as "discrimination of services with a goal to make them pay fees to gain priority connection" [7]. In the Netherlands the net neutrality is obligatory by law, in the USA the net neutrality is guaranteed in the Internet regulations issued by the Federal Communications Commission. In Russia this principle is stated in the recommendations of the responsible working group in the Federal AntiMonopoly Agency (FAMA), in this document it is stated that the goal of setting this principle is to remove barriers to accessing the desired content for end users, to make discrimination in internet connection services impossible, to enable cooperation between different market players for improving the quality of services and to ensure the safety of citizens and the state [8].

- right to internet connection services also has an economical component. In the whole world connecting to the Internet and providing internet services are handled by private companies that provide these services in exchange for payment. The duty of the state here is to ensure that internet access is affordable at a reasonable price for a wide range of its citizens.

- the right to comfortable use of internet services implies that certain technological standards will be put in place to ensure the quality of these services. Such standards include the speed and stability of internet traffic, requirements for the architecture of and navigation on websites, automated information search, the possibility to determine the date and time of publishing the information, conditions for copying and storing information from the Internet by the user, availability of the English version of the website or tools for its automatic translation into the most common world languages, the possibility to contact the content the website creators online, a special option for using the internet service by people with disabilities [9]. Part 2 of Article 57 of the Federal Law "About Means of Communication" states that data should be transmitted to the user's equipment with a speed not below 10 (ten) megabit per second. In 2020 Chapter 7.1 was added to this law, this new chapter sets new requirements for 
ensuring stable, safe and uniform functioning of the internet in the Russian Federation.

- the right not to be disconnected from the internet was first formulated in the verdict of the Constitutional Council of France on June 10, 2009. The Constitutional Council was reviewing the bill that proposed to punish the persons that on numerous occasions violated the copyright laws by distributing illegal copies of copyrighted materials on the Internet by disconnecting them from the Internet for a period from two months to one year without the right to get access from any other internet provider during this time [10]. The Constitutional Council declared that the bill was in conflict with the country's constitution since its creators hadn't considered the fundamental freedom of speech and communicating with others and the important role the telecommunication services play in democratic processes, so disconnecting a person from the Internet is a disproportionate punishment for such violations.

Later the right not to be disconnected from the Internet was enshrined in the above mentioned Human Rights Guide for internet Users (2014). It means that a person can't be disconnected from the Internet at will, such a decision can only be made by a court or by the internet provider in case of a contract obligations' violation. In this case providers are obligated to inform the users of the reasons and legal base of the disconnection, as well as procedures to appeal this decision and possibilities of applying for regaining full access to the Internet.

The right to internet access was further strengthened with the project "Accessible internet". On 15 January 2020 the Russian president Vladimir Putin in his annual address to the Federal Assembly made it a goal for the country's government to provide free internet access to socially relevant Russian internet services everywhere in the country. The four biggest telecommunication services providers in Russia supported the president's initiative. The Russian Ministry of Communications issued a decree with conditions for the experimental realization of this project and a list of 391 free internet resources [11]. The decree recommends the internet service providers "not to terminate internet services contracts even if the users haven't been paying for these services, but instead only give them access to the free socially relevant services". In other words, even if users stop paying for internet services they will still have limited access to these services in order to use the socially relevant internet resources.

The Russian laws provide liability for obstructing the work of internet websites or any actions aimed at a knowingly illegal restriction of access to websites (Article 13.18 of the Code of Administrative Offenses of the Russian Federation from 30 December 2001 no. 195Federal Law).

So, even though the right to internet access is a new right, its realization is to a certain degree already regulated by Russian law and can be defended on the administrative level or in court.

Another right that is predicated on the emergence and development of the Internet is the right to digital identity. It is connected with the possibility to manage the internet data of individuals.

The personal data that users submit to different service providers on the Internet, as well as the so called digital traces - information about the user's actions on the Internet - forms a digital portrait of the user, a projection of the real person in the virtual environment. This phenomenon is called a digital identity. In Law this phenomenon corresponds to the following two features: 1) the originality, individuality of each person; 2) digital form of data presentation; 3) the ability to "recognize" the user in the virtual environment, without confusing him with others, to be sure that the virtual projection of this person belongs to "him/her" and not to someone else.

The right to digital identity includes three aspects: its forming, use and protection.

The forming of the digital identity presumes the possibility for the users to know who and how collects their data and what data have already been gathered about them. Contemporary studies show that the internet users data that is being collected can be divided into different layers, and the data that people consciously and of at their own will provides to the information mediators or publish on blogs, social networks, mobile apps are only the first layer. But the information technologies nowadays allow collecting a lot of other data about users' behavior. For example, about their current location, the content they view, which keys they press on their keyboard, about their values, political views and consumer preferences, even about their psychological and emotional state. According to A.M. Kondakov and A.A. Kostylyova use of different algorithms for analyzing the user's web searches allows to find out everything about that person that he/she wouldn't voluntarily reveal about themselves: "their weaknesses, their psychometric profile and IQ level, family situation, addictions, illnesses, small obsessions (i.e. games) and their serious commitments (i.e. business projects)" [12].

This data can later be used by commercial companies for marketing their goods and services to that specific user or for social control like with the Social Credit System in China which uses information technologies to automatically assess the citizens' behavior and give them points based on this assessment. Citizens with a low social rating face restrictions for purchasing tickets, the rating is taken into account when a person wants to enter a university or get a job.

Protection of digital identity is especially necessary because of the rising number of personal data theft cases. A report of the International Electronic Communications Union with the telling name "Digital Life" contains results of a study analyzing the consequences of violating the right to digital identity. The victims of personal data theft (they are called "those who were stolen from themselves") lost their jobs, couldn't get student loans, mortgages or car loans and in some cases were even arrested for crimes they didn't commit. According to the data cited in the report the victims on average had to devote about 600 hours of their time to recover their digital identity, reputation and credit 
history. The emotional impact of this on the victims is comparable with that of violent crimes [13].

The General Data Protection Regulation (GDPR) that was put in place by the Resolution no.2016/679 of the European Parliament and the Councils of the European Union on 27 April 2016 and came into force in 2018 contains fundamentally new provisions for the protection of personal user data.

For example, it differentiates between the data that users submit by themselves (Article 13 of the Regulation) and the data about the user that are gained not from him/her (Article 14 of the Regulation). And the key is enabling the user to manage that latter set of data. In particular, the Regulation enshrines the user's right to inquire about what data, from which sources and for which purposes were gathered about him/her, about the legal base for using his/her data and about whether or not the gathered data will be used for automated decision making as well as the user's right to recall his/her consent to use of their data and the user's right to file a complaint with the overseeing authority.

In Russian Federation some aspects of the right to digital identity are regulated by Law on Information and the Federal Law "On Personal Data" from 27 July 2006 No. 152-Federal Law (hereinafter referred to as the Law on Personal Data), which establishes the requirements for receiving and use of personal data, as it is stated in the Law, "among other things in information and communication networks" (Art. 1). The Russian legislation establishes the requirement for the mandatory consent of the individual to the processing of his/her data.

The right to anonymity is one of the most controversial rights exercised on the Internet. The right to anonymity (from lat. "without a name") on the Internet means the ability to perform certain actions under a false name (nickname) without disclosing personal data that would allow the individual to be identified. Such actions usually include anonymous communication on social networks, commenting on articles, blogs, posts, sending private messages via instant messaging services, making online payments, distributing creative products (produced by themselves or others).

To date there is no binding international legislation securing the right to anonymity on the internet. Although the Report of the Special Expert on Ensuring and Protecting the Right to Freedom of Opinion and Expression of the UN Human Rights Council, David Kaye, dated 22 May 2015, that he presented at the 29th session of the UN Human Rights Council, advocates the idea that anonymity is necessary for exercising freedom of opinion in the digital environment and therefore requires international protection, but this report is only advisory in nature [14].

Russian legislation establishes a number of rules that prevent users from maintaining anonymity. Article 10 of the Law on Information establishes that information disseminated without using mass media must include reliable information about its owner or another person disseminating this information, in such form and amount that is sufficient to identify this person. In 2016, the
Russian parliament adopted the so-called Yarovaya's legislative package aimed at de-anonymizing users.

According to the new edition of Parts 3 and 3.1 of Article 10.1 of the Law on Information, the organizer of the information dissemination on the Internet is obliged to store on the territory of the Russian Federation information on the facts of reception, transmission, delivery and (or) processing of voice recordings, written text, images, sounds, video or other electronic messages of internet users and information about these users for one year from the end of the implementation of such actions, and the messages themselves - for six months. The organizer of the information dissemination on the Internet is obliged to disclose this information to the authorized state bodies when it is needed for an ongoing investigation or ensuring the security of the Russian Federation.

Another quite controversial issue are anonymous comments. If an Internet resource on which a comment containing signs of abuse of freedom of the media is posted is registered as a mass media, then Roskomnadzor (Federal Service for Supervision of Communications, Information Technology, and Mass Media) which monitors legislative compliance in this area will contact that media's editorial office and demand to delete the comment or edit it. Within one day, the editorial office must perform the required actions. Otherwise, Roskomnadzor has the right to issue a warning to that media. Two warnings within one year may result in the media being closed.

If an Internet resource is not registered as a mass media, but has a different legal status, the responsibility for anonymous messages on its website that violate the rights of third parties may be assigned to the site owner, since he/she is the domain administrator and therefore the person who has provided the necessary conditions and technical capabilities to visitors of his/her internet resource.

Next we consider the right to decline unsolicited information.

With the development of digital technologies, information messages can be repeatedly transmitted to a large number of recipients. This raises the question of protecting the user from information that he has not requested and does not want to receive. The right to reject unwanted information could be defined as the right to be protected from spam.

Electronic submissions, that were not approved by the user, are prohibited in accordance with Article 18 Part 1 of the Federal Act "On Advertising" of March 13, 2006 No. 38-Federal Law, which provides that the distribution of advertising via telecommunications networks, including the use of mobile phone, fax and cellular telephone communications, are only permitted to receive advertising with the prior consent of the subscriber or recipient.

In this case, the advertisement will be recognized as distributed without the prior consent of the subscriber or recipient, unless the merchant can prove that such consent has been obtained. 
The advertising distributor is obliged to immediately stop distributing advertising to the address of the person who made such a request.

In 2014, a provision was introduced in the Information Act obligating the organizer of the information distribution to ensure the technical ability of users of the instant messaging service to refuse to receive electronic messages from other users.

Currently the register of organizers of information distribution, which is maintained by Roskomnadzor includes the social networks Vkontakte, Moy Mir, Odnoklassniki, the Yandex service complex, the Mail.ru mail service, Telegram and Sberbank messengers, cloud storages, online publications, electronic magazines, news agencies, forums, blogs that provide services for the exchange of text messages, audio, photo and video information in real time between clients.

Therefore, a binding regulation applies to all mailings, regardless of their content and the electronic platforms used, in order to guarantee the possibility of rejecting the information sent.

The introduction of the right to oblivion can be traced back to the development of digital technologies for finding and storing information on the Internet. Back in the day, before the Internet, if information about events, phenomena or actions of an individual was published, for example, in the media, after a while it lost all its relevance, copies of newspapers or television programs were transferred to the archives, the event itself was forgotten, where in the conditions in which information is displayed in Internet resources, it is always available (i.e., its distribution is no longer one-time event ) and can be easily found using search engines. In academic literature, the right to be forgotten is linked to the constitutional principle of humanism, the ability of a person to receive forgiveness, and the right to further personal development [6].

The origins of the right to be forgotten are associated with the decision of the European Court of Justice (ECJ) of 13 May 2014 in the case of Gonales v. Google. In 2010, Spanish citizen Costeja Gonales filed a complaint against Google Span with the National Data Protection Authority which stated that when entering his name into the Google Group search engine, he received links to the 1998 newspaper page, which published the advertisement about the sale of his house at auction in connection with the collection of debts for non-payment of contributions to the Social Security Fund. The applicant requested that the ad be removed and that this information no longer be included in search results. The agency denied him a request to remove the ad in reference to the legal validity of such a post, but supported the request to Google to remove the corresponding links. The company tried to challenge the Agency's decision before the Supreme Court of Spain, which, when examining the case, referred the matter to the EU Court of Justice. In its decision, the Court of Justice of the European Union recognized the right of a natural person to demand to stop the publication of links containing harmful information about them [15].

Subsequently, the right to erasure was enshrined in Article 17 of the aforementioned General Data
Protection Regulation (GDPR), where it is referred to as "the right to be forgotten". Part 1 of this GDPR article enshrines the subject's right to demand the erasure of his own data in cases where: the purposes for which they were collected and processed have been exhausted; the consent to data processing has been revoked; the data has been processed unlawfully, etc.

A.A. Antopolsky points out that "the right to be forgotten is protected as part of the right to respect the private life, provided for in Article 8 of the Treaty.

At the same time, it frequently conflicts with the freedom of expression, but the first steps have already been taken to achieve a "fair balance" between the protection of each of these rights " [16].

In Russia, the right to be forgotten was enshrined in law earlier than in many other European countries.

In 2015, Article 10.3 was added to the Information Act requiring the operator of the search engine, at the request of the citizen, to stop providing information on a website index on the Internet, allowing access to information about the applicant.

Links must be disabled when the information:

- is distributed in violation of Russian legislation;

- is unreliable;

- is outdated, has lost its meaning for the applicant due to subsequent events or actions of the applicant.

The Internet is not a law-free space; on the contrary, today it is already a regulated and controlled communication space. However, most of the Internet has market-based Amor-regulation, its "code is law" tool. New Network architecture, new search algorithms, and new types of information selection and connection are emerging faster than ever. Therefore, it is important to guarantee an effective and open to innovation communication-free legal framework, which is the task of a democratic legislator to create [17].

\section{Conclusion}

Hence, the new digital rights have already been largely consolidated both in international legal acts and in Russian legislation. The mechanisms for their implementation and protection have been developed by national legislators to varying degrees and need to be further improved

\section{References}

1. Y. Sinelschikova, 10 facts about the Russian Internet

(2016),

URL://https://www.rbth.com/science and tech/201 6/01/11/10-facts-about-the-russian-internet 558165 (date of access: 16.03.21)

2. A.T. Karasev, O.A. Kozhevnikov, \& V.A. Meshcheryagina, Antinomies 19 (3), 99-119 (2019)

3. Shah, The Internet and Human Rights. Global Issues. Web. $02 \quad$ Nov. 2020. URL:https://www.globalissues.org/article/151/theinternet-and-human-rights(date of access: 16.03.21) 
4. M.S. Salikov, \& S.E. Nesmeyanova, Russian law, education, practice, science 1, 5-13 (2019)

5. E.V. Talapina, Law of the Russian Academy of Sciences 14(3), 122-146 (2019)

6. E.A. Voinikanis, Pravovedenie 3, 70-89 (2016)

7. Institute for Internet Research. Network Neutrality or Long Distance Internet (2020) URL: // https://internetinstitute.ru/ (date of access: 16.03.21)

8. Federal Antimonopoly Service of the Russian Federation. Basic Document on Net Neutrality (2020) URL: // http://fas.gov.ru/upload/other(date of access: 16.03.21)

9. V.N. Sereda, \& M.Yu Sereda, Protection of human and civil rights and freedoms on the Internet (Voronezh. Russian Federation: Publishing and Printing Center "Scientific Book", 2013).

10. L.B. Sitdikova, A.L. Shilovskaya, M.A. Volkova, R.R. Lenkovskaya, \& N.A. Stepanova, Mediterranean Journal of Social Sciences 6(6), 163-169 (2015).

11. Ministry of Digital Development, Communications and Mass Media of the Russian Federation On conducting an experiment on the provision of communication services to citizens on a pro bono basis for the transfer of data and for providing access to the information and telecommunication network "Internet" on the territory of the Russian Federation for the use of socially significant information resources in the information and communication network "Internet": order of the Ministry of Digital Development, communications and mass communications of the Russian Federation from 31.03.2020, No. 148 (2020)

12. A.M. Kondakov, \& A.A. Kostyleva, Vestnik RUDN. Series: Informatization of education. 16 (3), 210 (2019)

13. International Telecommunication Union, Digital Life (2006) URL: https://www.itu.int/osg/spu/publications/digitalife/d ocs/digital-life-web.pdf (date of access: 16.03.21)

14. David Kaye, Report of the Special Rapporteur on the promotion and protection of the right to freedom of opinion and expression (2016) URL: // https://ru.euronews.com/2016/07/05/un-denouncesdisruption-of-internet-access-as-human-rightsviolation (date of access: 15.04.21)

15. A.A. Chebotareva, Legal support of personal information security in the global information society (Dissertation for the degree of Doctor of Law), (Moscow, Russian Federation, 2017)

16. A.A. AntopolskyHuman Proceedings of the Institute of State and Law of the Russian Academy of Sciences 14(2), 159-185, (2019)

17. M. Kall, Impulspapiere. Münster 2, 1-86 (2011) 